\title{
EVALUATION OF LONG TERM TREND OF DIFFERENT DROUGHT INDICES USING MANN-KENDALL AND SEN'S SLOPE ESTIMATOR OVER IRAN
}

\author{
S. Zakeri ${ }^{1 *}$, A. Samkhaniani ${ }^{2}$, S. Adeli ${ }^{1}$, Z. Nikraftar ${ }^{1}$ \\ ${ }^{1}$ School of Surveying and Geospatial Engineering, College of Engineering, University of Tehran, Tehran, Iran - (zakeri.salar, \\ sarina.adeli, xahir.nikraftar)@ut.ac.ir \\ ${ }^{2}$ Babol Noshirvani University of Technology, Civil Engineering Department, P.O. Box484, Shariati Ave., Babol, Mazandaran \\ 47148-71167, Iran - (ali.sam@ nit.ac.ir)
}

\section{Commission VI, WG VI/4}

KEY WORDS: Mann-Kendall, Sen's slope estimator, drought, Standardized Precipitation Index, Standardized Soil moisture Index, Total Storage Deficit Index

\begin{abstract}
:
Historically droughts have had a huge impact on conditions of life on earth. With growing population of the Earth the impacts of droughts grow even more severe. Human beings are also affected by drought like other life forms. Studies have taken place to understand and thereby mitigate the effects of these climatological phenomena on humans. The study of drought trends is of great importance since it is directly related to food and water resources availability, that could become scarce in case of droughts. In this paper by using SPI, SSI and TSDI indices we try to understand the drought behaviour in Iran using Mann-Kendall and Sen's slope methods. Canonical correlation analysis between SPI and SSI shows a positive correlation for the most parts of Iran. Also the correlation between TSDI and SPI/SSI is positive for majority of the Iran. Drought trends in Iran are analysed using Mann-Kendall and Sen's slope estimator with $95 \%$ confidence level.
\end{abstract}

\section{INTRODUCTION}

Drought is defined as an abnormal dry weather sufficiently prolonged due to shortage in rainfall, causing the area to suffer from hydrological imbalances. In current century climate change is known to be a major threat. The effects of natural disaster known as drought could get even worse by poor management of water, land, forest and other natural resources (Mahajan and Dodamani, 2015). There are five categories for drought, such as: Meteorological drought, hydrological drought, agricultural drought, socioeconomic drought and ground water drought (Mishra and Singh, 2010). Lack of rainfall could result in drought on the other hand heavy rainfall in a short period of time could result in floods. areas that mostly have an arid and semi-arid climate such as Iran are prone to be affected by climate change more severely (Parry et al., 2004). Iran is located in a region where water resources are scarce and because of its agriculture relying on climate, is very vulnerable to climate change (Nassiri et al., 2006). Iran's availability of fresh water per capita per year in the year 2000 was $2000 \mathrm{~m} 3$ where as it is predicted the amount would decrease to $1500 \mathrm{~m} 3$ per capita per year by the year 2030 (Yang et al., 2003). Iran has diverse climatic conditions. Some regions with significant rainfall while some are dry and suffer from water scarcity (Abbaspour et al., 2009). One of more noticeable climate changes has occurred in north-eastern Iran with a reduction in precipitation (Evans, 2009). Agriculture being one of biggest consumers of water is also one of the most susceptible to climate change in Iran (Karimi et al., 2018). This paper aims to acquire a better understanding of drought trend in Iran using three different indices, Standardized Precipitation Index (SPI), Standardized Soil Moisture Index (SSI) and Total Storage
Deficit Index (TSDI). A canonical correlation has been used between the indices to find suitable time scales for detecting and finding the trends.

\section{STUDY AREA AND INDICES}

Iran was selected for this study to assess the drought trends by Mann-Kendall slope method. Iran is located in middle east, in south-west of Asian continent. In the north Caspian and in the south the Persian Gulf and Oman sea border Iran. Iran has seven neighbouring countries including Afghanistan, Armenia, Azerbaijan, Iraq, Pakistan, Turkey and Turkmenistan. Iran has an area of 1648195 square $\mathrm{km}$, and is contained within the latitudes of $25^{\circ} 14$ and $39^{\circ} 42 \mathrm{~N}$ and longitudes of $44^{\circ} 10$ and $64^{\circ} 11 \mathrm{E}$. The elevation of the country varies from sea level to $5604 \mathrm{~m}$ at peak of Damavand mountain the highest point of the country. Climate of Iran is diverse but most of the country have arid or semi-arid climate and the mean annual rainfall ranges from $50 \mathrm{~mm}$ in central parts to $2000 \mathrm{~mm}$ in lowlands surrounded by Caspian Sea and Alborz mountain range.

\subsection{Standardized precipitation index}

(McKee et al., 1993) introduced SPI based on precipitation data for drought monitoring. Standardized Precipitation index (SPI) is a meteorological index and is typically derived by fitting a gamma probability distribution function to precipitation data. SPI could be used to monitor drought with different time scales. $\mathrm{x}$ follows a gamma distribution and it shows precipitation in a region as following:

Corresponding author 


$$
\begin{aligned}
& f(x)=\frac{1}{\beta^{\alpha} \Gamma(\alpha)} x^{\alpha-1} e \frac{-x}{\beta} \\
& \Gamma(\alpha)=\int_{0}^{\infty} y^{\alpha-1} e^{-y} d y
\end{aligned}
$$

where $\alpha$ is shape factor and $\beta$ is scale factor of the distribution. $\Gamma(\alpha)$ is gamma function.

The optimal values for $\alpha$ and $\beta$ are found as following:

$$
A=\ln (\bar{x})-\frac{\sum \ln (x)}{n}
$$

Where $\mathrm{n}$ is the number of data.

$$
\begin{aligned}
& \hat{\alpha}=\frac{1}{4 A}\left[1+\sqrt{1+\frac{4 A}{3}}\right] \\
& \hat{\beta}=\frac{\bar{x}}{\hat{\alpha}}
\end{aligned}
$$

after the gamma distribution parameters are determined gamma cumulative distribution function is used to calculate SPI as following:

$$
F(x)=\int_{0}^{\infty} f(x) d x=\frac{1}{\hat{\beta}^{\hat{\alpha}} \Gamma(\hat{\alpha})} x^{\hat{\alpha}-1} e \frac{-x}{\hat{\beta}} d x
$$

\subsection{Standardized Soil moisture Index}

Soil moisture data is used to calculate an index called standardized soil moisture index for drought warning. SSI is based on concept of normal precipitation it is also based on Palmer Z index along with statistical construct of SPI. SSI basically uses the $\mathrm{z}$-score to explain how much the soil moisture deviates from the historical mean of soil moisture and in this manner it identifies outliers in the time series as droughts (Xu et al., 2018).

\subsection{Total Storage Deficit Index}

TSDI was introduced by (Yirdaw et al., 2008) it could be calculated from observations made by GRACE. It was driven from PDSI Palmer and Soil Moisture Deficit Index (HosseiniMoghari et al., 2019). TSDI consists of calculation of total storage deficit along with a drought monograph determination (Cao et al., 2015).

TSD is calculated as following:(Yirdaw et al., 2008)

$T S D I_{i, j}=\frac{T W S A_{i, j}-T W S A_{j}}{\operatorname{Max}\left(T W S A_{j}\right)-\operatorname{Min}\left(T W S A_{j}\right)} \times 100$

where $\operatorname{TSD}_{i, j}$ is the total storage deficit of the jth month of ith year, TWSA $A_{i, j}$ is total water storage anomaly from GRACE in the jth month of ith year.

TWSA $_{j}$ is calculated from averaging TWSA during $j$ th month. The Max (TWSA $A_{j}$ is the maximum of TWSA of $j$ th month, and Min $\left(T_{W S A}\right)$ is the minimum of TWSA of jth month.
After the calculation of the TSD time series, in the next step TSDI is calculated from the previous TSDI and the current TSD as follows:

$$
T S D I_{k}=p \times T S D I_{k-1}+q \times T S D_{k}
$$

According to (Yirdaw et al., 2008) $\mathrm{p}$ and $\mathrm{q}$ are obtained from cumulative TSD plot during dry period.

A canonical correlation is calculated between 6 months and 12 months SPI and SSI indices. 12-month correlation proved to be higher therefor it was selected for future calculations.

\section{PROPOSED METHOD}

A drought index is typically a single value which represents the severity of a drought. It is more useful than raw data for the purpose of understanding drought conditions (Mahajan and Dodamani, 2015). Both parametric and non-parametric analysis methods are used for the trend analysis. Linear regression is a parametric method with Man-Kendall Test is a nonparametric method. When data is independent and normally distributed parametric methods are more powerful than non-parametric methods A non-parametric test is more capable than parametric test to evade problems caused by data skew (Smith, 2000).

The non-parametric test for detecting trend was formulated by Mann (Mann, 1945) and the statistic distribution test was introduced by Kendall (Kendall, 1975) in order to test turning point and non-linear trend. For detection of trend in hydrometeorological time series Man-Kendall test is a better tool compared to spearman's rho(another non-parametric test) (Yue et al., 2002). In addition, when testing various stations in a single study Man-Kendall test is more suitable (Hirsch et al., 1991)

\subsection{Mann-Kendall}

In the next step Mann-Kendall method is used to understand if actually there is a trend in the calculated indices Mann-Kendall statistic $\mathrm{S}$ is as following:

$$
S=\sum_{i=1}^{n-1} \sum_{j=i+1}^{n} \operatorname{sgn}\left(\mathrm{x}_{j}-\mathrm{x}_{i}\right)
$$

The test is used on a time series

$$
\begin{aligned}
& T_{i}=\frac{x_{j}-x_{k}}{j-k} \\
& \operatorname{Sgn}\left(\mathrm{x}_{j}-x_{i}\right)=\left\{\begin{array}{l}
+1,\rangle\left(\mathrm{x}_{j}-\mathrm{x}_{i}\right) \\
0,=\left(\mathrm{x}_{j}-\mathrm{x}_{i}\right) \\
-1,>\left(\mathrm{x}_{j}-\mathrm{x}_{i}\right)
\end{array}\right.
\end{aligned}
$$

The variance statistic is:

$$
\operatorname{Var}(\mathrm{S})=\frac{n(n-1)(2 n+5)-\sum_{i=1}^{m} t(\mathrm{i})(\mathrm{i}-1)(2 \mathrm{i}+5)}{18}
$$


The test statistic $Z_{c}$ is calculated as following:

$$
Z_{c}=\left\{\begin{array}{l}
\frac{S-1}{\sqrt{\operatorname{Var}(\mathrm{s})}}, S>0 \\
0, S=0 \\
\frac{S-1}{\sqrt{\operatorname{Var}(\mathrm{s})}}, S\langle 0
\end{array}\right.
$$

Positive or negative values of $Z_{c}$ respectively signify an upward or downward trend.

In case $Z_{c}$ is greater than $Z_{\alpha}$ where $\alpha$ is the significance level; then the trend is significant. Significance level are usually assigned low values. The greater the value of $\alpha$, there is less confidence that the null hypothesis is really false when it has been identified to be false. Afterwards Sen's slope is applied to calculate the trend.

\subsection{Sen's slope estimator test}

Sen's estimator predicts the magnitude of the trend (Sen, 1968). The slope $\left(T_{i}\right.$ ) of all pairs of data is calculated:

$T_{i}=\frac{x_{j}-x_{k}}{j-k}$

where $x_{j}$ and $x_{k}$ are data values at times $j$ and $k$ respectively. Sen's estimator of slope is defined as the median of these $\mathrm{N}$ values of $\mathrm{T}_{\mathrm{i}}$

If $\mathrm{N}$ is odd:

$$
Q_{\text {med }}=\frac{T(\mathrm{~N}+1)}{2}
$$

And if $\mathrm{N}$ is even:

$Q_{\text {med }}=\frac{\left[\frac{T N}{2}+\frac{T(\mathrm{~N}+2)}{2}\right]}{2}$

\section{RESULTS AND CONCLUSION}

Canonical correlation analysis between SPI and SSI shows a positive correlation for the most parts of Iran excluding central and south-western part which show a negative correlation. This could be due to delay response Soil moisture to rainfall. Although between TSDI and SPI/SSI correlation is positive for majority of the Iran except for north-western part. This reverse behaviour of TSDI compared to SPI/SSI in north-western part has been discussed in many researches and it has been indicated that it's because of extreme contribution of human factor in ground water desiccation, to an extent that increase in rainfall could not recover the ground water depletion.

Long-term trend analysis of these time series has been conducted in a pixel wise basis. As portrayed in fig. 4 and fig. 5 , there is a positive trend for SPI and SSI indices in north and north western parts of Iran while in western and central parts of Iran, negative trend is observable. The main reason behind the negative trend existence in western and central parts of Iran is that low pressure front originating from West has been restricted by Alborz and Zagros mountain ranges.

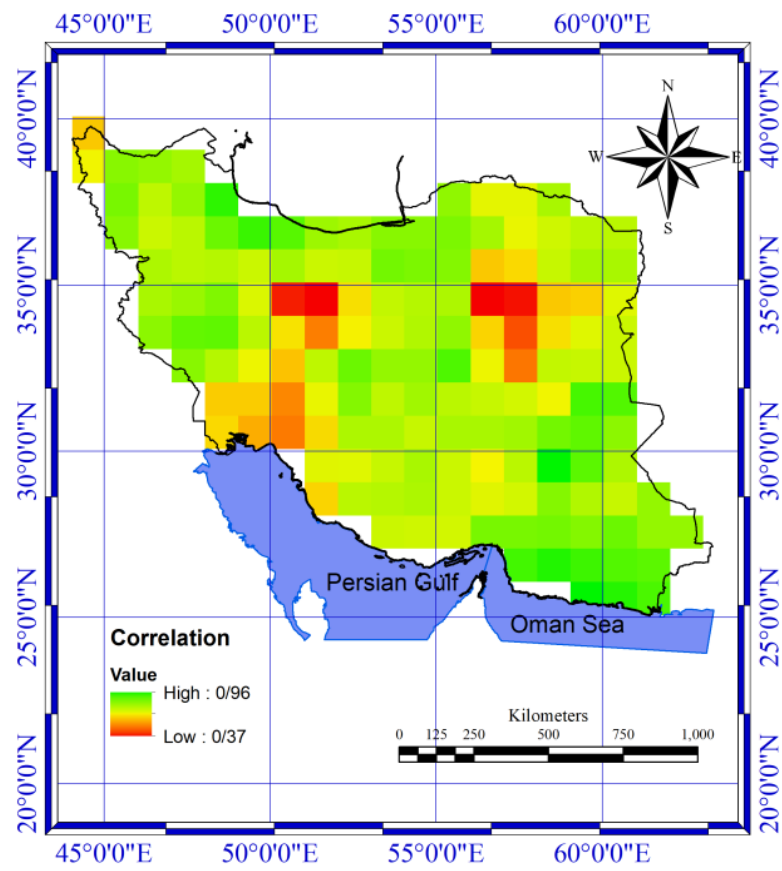

Figure 1. SPI/SSI correlation 


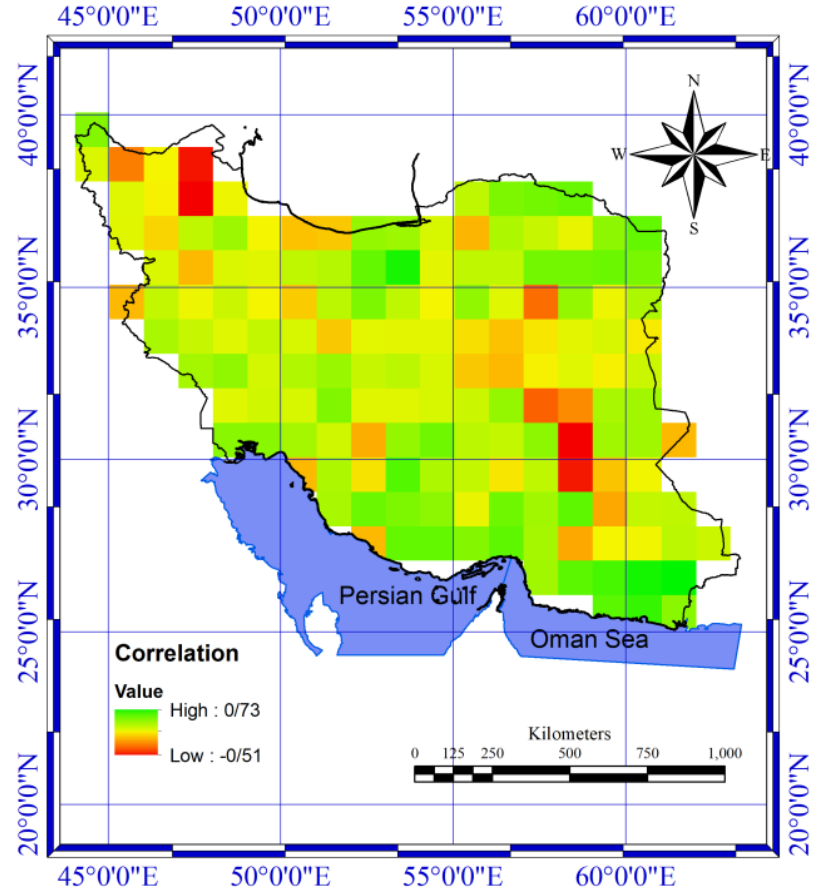

Figure 2. SPI/TSDI correlation

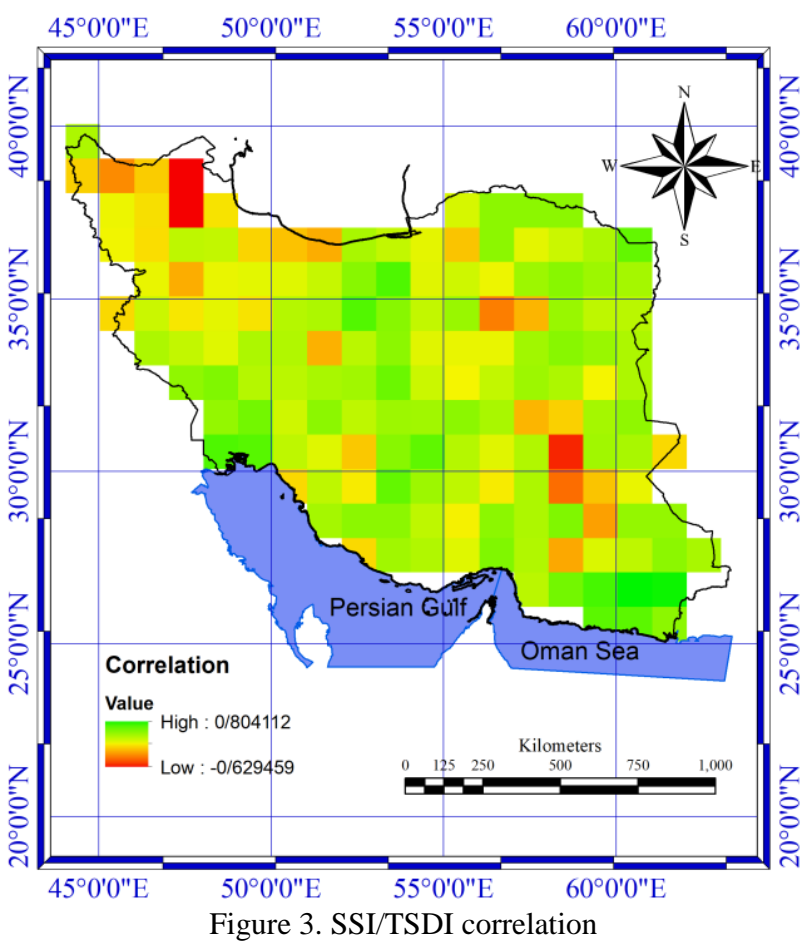

Figure 3. SSI/TSDI correlation

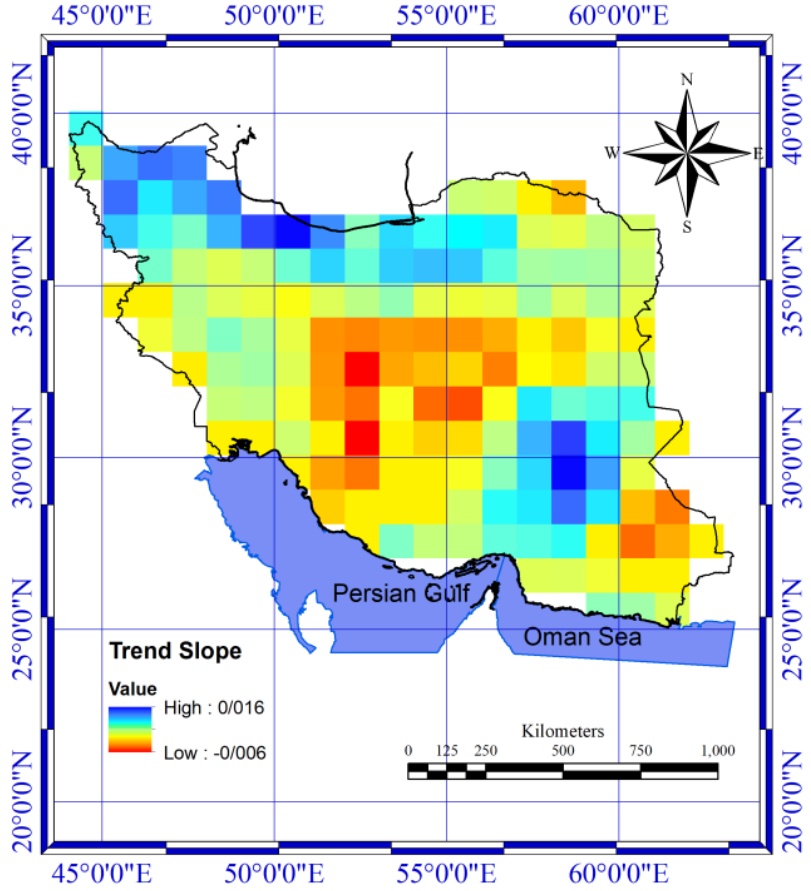

Figure 4. SPI slope

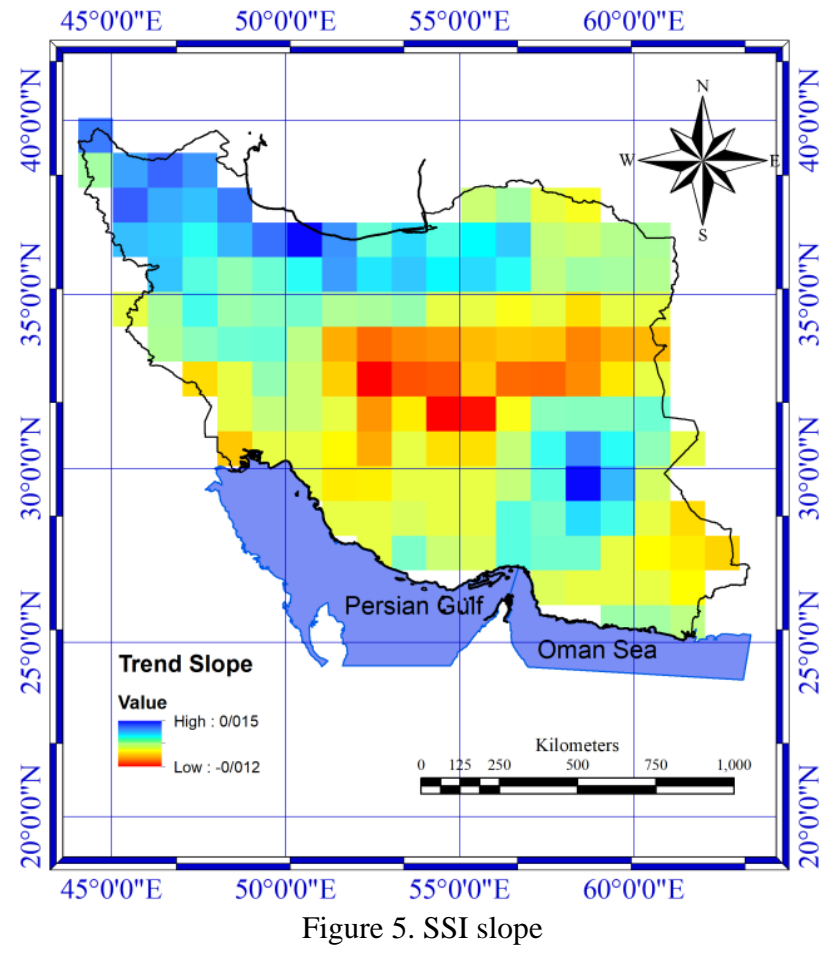




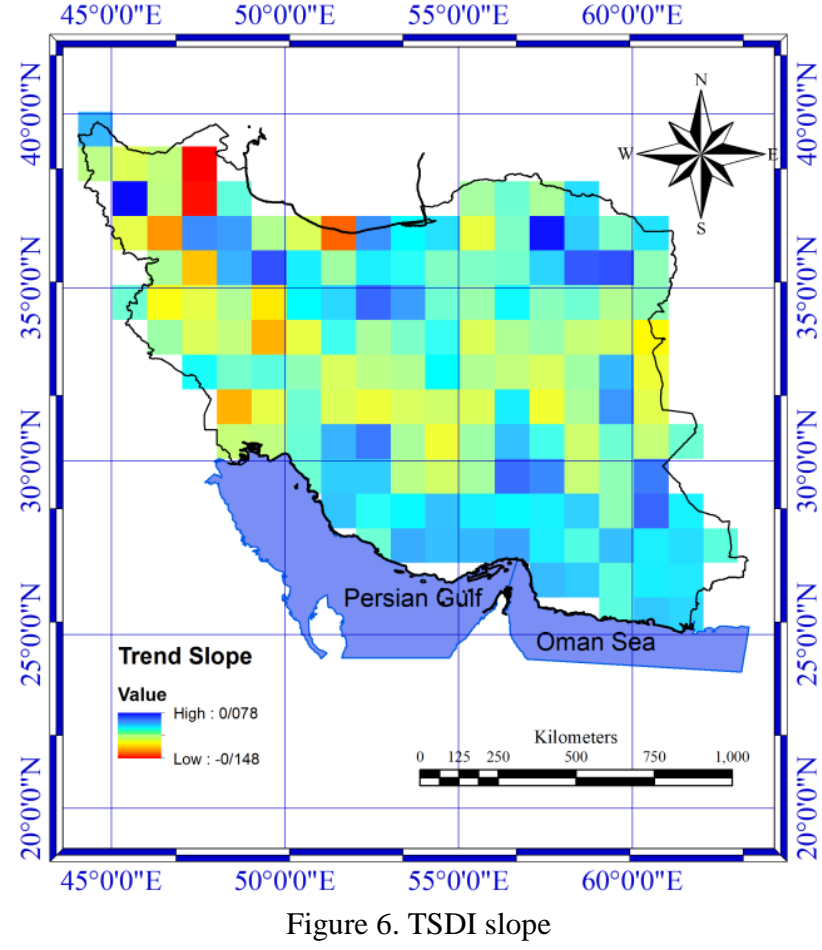

REFERENCES

Abbaspour, K.C., Faramarzi, M., Ghasemi, S.S., Yang, H., 2009. Assessing the impact of climate change on water resources in Iran. Water Resour. Res. https://doi.org/10.1029/2008WR007615

Cao, Y., Nan, Z., Cheng, G., 2015. GRACE gravity satellite observations of terrestrial water storage changes for drought characterization in the arid land of northwestern China. Remote Sens. https://doi.org/10.3390/rs70101021

Evans, J.P., 2009. 21st century climate change in the Middle East. Clim. Change. https://doi.org/10.1007/s10584-0089438-5

Hirsch, R.M., Alexander, R.B., Smith, R.A., 1991. Selection of methods for the detection and estimation of trends in water quality. Water Resour. Res. https://doi.org/10.1029/91WR00259

Hosseini-Moghari, S.M., Araghinejad, S., Ebrahimi, K., Tourian, M.J., 2019. Introducing modified total storage deficit index (MTSDI) for drought monitoring using GRACE observations. Ecol. Indic. https://doi.org/10.1016/j.ecolind.2019.01.002

Karimi, V., Karami, E., Keshavarz, M., 2018. Climate change and agriculture: Impacts and adaptive responses in Iran. J. Integr. Agric. https://doi.org/10.1016/S20953119(17)61794-5

Kendall, M.G., 1975. Rank Correlation Methods, Charles Griffin.

Mahajan, D.R., Dodamani, B.M., 2015. Trend Analysis of Drought Events Over Upper Krishna Basin in Maharashtra. Aquat. Procedia. https://doi.org/10.1016/j.aqpro.2015.02.163

Mann, H.B., 1945. Nonparametric Tests Against Trend. Econometrica. https://doi.org/10.2307/1907187

McKee, T.B., Nolan, J., Kleist, J., 1993. The relationship of drought frequency and duration to time scales. Prepr. Eighth Conf. Appl. Climatol. Amer. Meteor, Soc.

Mishra, A.K., Singh, V.P., 2010. A review of drought concepts. J. Hydrol. https://doi.org/10.1016/j.jhydrol.2010.07.012

Nassiri, M., Koocheki, A., Kamali, G.A., Shahandeh, H., 2006. Potential impact of climate change on rainfed wheat production in Iran. Arch. Agron. Soil Sci. https://doi.org/10.1080/03650340600560053

Parry, M.L., Rosenzweig, C., Iglesias, A., Livermore, M., Fischer, G., 2004. Effects of climate change on global food production under SRES emissions and socioeconomic scenarios. Glob. Environ. Chang. https://doi.org/10.1016/j.gloenvcha.2003.10.008

Sen, P.K., 1968. Estimates of the Regression Coefficient Based on Kendall's Tau. J. Am. Stat. Assoc. https://doi.org/10.1080/01621459.1968.10480934

Smith, L.C., 2000. Trends in russian arctic river-ice formation and breakup, 1917 to 1994 . Phys. Geogr. https://doi.org/10.1080/02723646.2000.10642698

Xu, Y., Wang, L., Ross, K.W., Liu, C., Berry, K., 2018. Standardized soil moisture index for drought monitoring based on soil moisture active passive observations and 36 years of North American Land Data Assimilation System data: A case study in the Southeast United States. Remote Sens. https://doi.org/10.3390/rs10020301

Yang, H., Reichert, P., Abbaspour, K.C., Zehnder, A.J.B., 2003. A water resources threshold and its implications for food security. Environ. Sci. Technol. https://doi.org/10.1021/es0263689

Yirdaw, S.Z., Snelgrove, K.R., Agboma, C.O., 2008. GRACE satellite observations of terrestrial moisture changes for drought characterization in the Canadian Prairie. J. Hydrol. https://doi.org/10.1016/j.jhydrol.2008.04.004

Yue, S., Pilon, P., Cavadias, G., 2002. Power of the MannKendall and Spearman's rho tests for detecting monotonic trends in hydrological series. J. Hydrol. https://doi.org/10.1016/S0022-1694(01)00594-7 